\title{
GnRH antagonist alters the migration of endometrial epithelial cells by reducing CKB
}

\author{
Qian Chen ${ }^{1,2, *}$, Yong Fan,*, Xiaowei Zhou², Zheng Yan³, Yanping Kuang ${ }^{3}$, Aijun Zhang ${ }^{1,2}$ and \\ Chen $\mathrm{Xu}^{1}$ \\ ${ }^{1}$ Department of Histo-Embryology, Genetics and Developmental Biology, Shanghai Jiaotong University, School of \\ Medicine, Shanghai Key Laboratory of Reproductive Medicine, Huangpu, Shanghai, China, ${ }^{2}$ Center of Reproductive \\ Medicine, Ruijin Hospital, Shanghai Jiaotong University, School of Medicine, Huangpu, Shanghai, China and \\ ${ }^{3}$ Department of Assisted Reproduction, Shanghai Ninth People's Hospital, Shanghai Jiaotong University, School of \\ Medicine, Huangpu, Shanghai, China
}

Correspondence should be addressed to Y Kuang or A Zhang or C Xu; Email: kuangyanp@126.com or zhaj1268@163.com or chenx1955@126.com

*(Q Chen and Y Fan contributed equally to this work)

\begin{abstract}
Some studies have demonstrated that the implantation rate of fresh transfer cycles is lower in the gonadotropin-releasing hormone antagonist (GnRH-ant) protocol than in the GnRH agonist (GnRH-a) protocol during in vitro fertilization (IVF). This effect may be related to endometrial receptivity. However, the mechanisms are unclear. Here, endometrial tissues obtained from the mid-secretory phase of patients treated with $\mathrm{GnRH}-\mathrm{a}$ or $\mathrm{GnRH}$-ant protocols and from patients on their natural cycle were assessed. Endometrial expression of B-type creatine kinase (CKB), which plays important roles in the implantation phase, was significantly reduced in the $\mathrm{GnRH}$-ant group. At the same time, expression of the endometrial receptivity marker HOXA10 was considerably reduced in the GnRH-ant group. GnRH-ant exposure in endometrial epithelial cells (EECs) in vitro decreased CKB expression and ATP generation and blocked polymerization of actin. Furthermore, in vitro GnRH-ant-exposed Ishikawa cells showed enhanced F-actin depolymerization, and these effects were rescued by $C K B$ overexpression. Similar effects were observed after $C K B$ knockdown, and these effects were rescued by $C K B$ overexpression. Moreover, cell migration was decreased in $C K B$-knockdown Ishikawa cells compared with that in control cells, and this effect was also rescued by $C K B$ overexpression. Overall, these findings showed that GnRH-ant affected CKB expression in EECs, resulting in cytoskeletal damage and migration failure. These results provide insight into the roles and molecular mechanisms of $\mathrm{GnRH}$-ant treatment in the endometrium.

Reproduction (2020) $159733-743$
\end{abstract}

\section{Introduction}

Gonadotropin-releasing hormone antagonist (GnRH-ant) and $\mathrm{GnRH}$ agonist $(\mathrm{GnRH}-\mathrm{a})$ protocols are the two main clinical protocols for controlled ovarian stimulation (COS) in in vitro fertilization-embryo transfer (IVF-ET) (Devroey et al. 2009). Although still unclear, many studies and meta-analyses have suggested that the implantation and pregnancy rates of fresh transfer cycles are lower in the $\mathrm{GnRH}$-ant protocol than in the $\mathrm{GnRH}$-a protocol (Al-Inany et al. 2007, Orvieto \& Patrizio 2013, Lambalk et al. 2017). In a previous study conducted at our center, the clinical pregnancy rate (PR) in the $\mathrm{GnRH}$-ant protocol was about $20 \%$ less than that in the $\mathrm{GnRH}$-a protocol (32 vs 51\%) (Xu et al. 2018). Further investigations have suggested that this observation may be related to endometrial receptivity. For example, although topquality embryo and blastocyst formation rates achieved using the $\mathrm{GnRH}$-ant protocol have been shown to be equivalent to those using the $\mathrm{GnRH}$-a protocol, the overall pregnancy rate is reduced when using the $\mathrm{GnRH}$ ant protocol (Bukulmez et al. 2008). Interestingly, this tendency is not observed when IVF-ET is performed using frozen embryos (Eftekhar et al. 2012). Similarly, a previously conducted donor-egg cycle analysis indicated that the recipient implantation rate (IR) and PR were not significantly different in patients receiving GnRH-antor GnRH-a-cycle-derived embryos (Prapas et al. 2005), and the results of mouse experiments have suggested that $\mathrm{GnRH}$-ant can reduce the expression of endometrial receptivity markers, such as HOXA10, LIF, and ITGB3 (Ruan et al. 2006, Li et al. 2015). Immunohistochemical analysis of human endometrial samples also showed that HOXA10 protein expression decreased significantly during the window of implantation (WOI) in the $\mathrm{GnRH}$ ant cycle (Rackow et al. 2008). Collectively, these 
results suggested that the negative effects of $\mathrm{GnRH}$-ant on pregnancy outcomes were likely to occur at the endometrial rather than the ovular or embryonic level (Hernandez 2000, Tarlatzis \& Bili 2003) and that GnRHant may adversely affect endometrial function and subsequently prevent embryo implantation; however, the specific mechanism is still unclear.

Key biological mechanisms, including energy metabolism and cytoskeleton remodeling, underlie human endometrial receptivity (Chen et al. 2015). Additionally, dynamic changes in the endometrium, which occur during the menstrual cycle, have high metabolic demand (Kim \& Moley 2009). Previous studies demonstrated that the 'brain' or 'B'-type creatine kinase $(\mathrm{CKB})$ is upregulated dramatically during the receptive phase (Chen et al. 2015), thereby mediating energy metabolism. The important role of CKB in metabolite regulation has been demonstrated in malignant cells (Loo et al. 2015). Creatine is phosphorylated by CKB, yielding phosphocreatine, which acts as a metabolic kinase to promote cancer progression. However, few reports have described the role of CKB in endometrial receptivity.

Further, GnRH-ant may adversely affect endometrial function by regulating the expression of CKB, and this may be the potential mechanism underlying its antagonist effects. Accordingly, the present study investigated CKB expression and ATP changes in the mid-secretory phase endometrium in IVF cycles to provide insight into defects that could contribute to implantation failure.

\section{Materials and methods}

\section{Patients}

This study was conducted in accordance with the guidelines of the Declaration of Helsinki. Written informed consent was obtained from all patients for their participation in this study, which was approved by the Institutional Ethics Committee of Ruijin Hospital, Shanghai Jiaotong University School of Medicine (no. 2012-57). Women aged 25-32 years who received IVF treatment for tubal obstruction at the Reproductive Medical Center of Ruijin Hospital and who gave up fresh embryo transfers owing to personal reasons were recruited. The inclusion and exclusion criteria were described previously (Chen et al. 2015). Furthermore, all the women included in these analyses had given birth to live babies after subsequent frozen embryo transfer (FET) treatments with natural cycle.

\section{Study design and groups}

Patients were classified into three groups. In the first group (GnRH-ant group), patients received controlled ovarian stimulation via administration of 150-225 IU/day of recombinant follicle-stimulating hormone ( $\mathrm{rFSH}$; Gonal-F; Merck Serono) beginning on the second day of their menstrual cycle when their estradiol $\left(E_{2}\right)$ level was less than $80 \mathrm{pg} / \mathrm{mL}$ and no ultrasound follicles with a maximum diameter of greater than $10 \mathrm{~mm}$ were detected. After 5 days of stimulation, or when at least one follicle with a diameter of greater than or equal to $14 \mathrm{~mm}$ was visualized, patients were subcutaneously administered $0.25 \mathrm{mg} /$ day GnRH antagonist (Cetrotide; Merck Serono) until human chorionic gonadotropin (hCG)-mediated ovulation induction. The second group ( $\mathrm{GnRH}-\mathrm{a}$ group) included patients whose pituitary function was reduced via s.c. administration of $0.1 \mathrm{mg} /$ day $\mathrm{GnRH}-\mathrm{a}$ (Decapeptyl; Ferring, Kiel, Germany) during the middle luteal phase of their preceding cycle. The above described $\mathrm{rFSH}$ injections were initiated once patient pituitary function was confirmed to be suppressed (as indicated by $E_{2}$ levels of less than $50 \mathrm{pg} / \mathrm{mL}$, with no cysts or ultrasound follicles greater than $10 \mathrm{~mm}$ ) and continued until the day of hCG-mediated ovulation induction.

The follicular growth in patients in the $\mathrm{GnRH}$-ant and $\mathrm{GnRH}-\mathrm{a}$ groups was evaluated using transvaginal ultrasound, and plasma $E_{2}, \mathrm{LH}$, and progesterone levels were measured using a commercially available immunoassay kit (BeckmanCoulter, CA, USA) to allow adjustment of the initial ovulationstimulation dose of rFSH. Specifically, 5000 IU hCG (LiZhu, Zhuhai, China) was administered to patients upon detection of at least two follicles with a diameter greater than $18 \mathrm{~mm}$, and oocyte retrieval was performed $36 \mathrm{~h}$ later by transvaginal ultrasound-guided follicle aspiration. Patients who elected to have all embryos cryopreserved for personal reasons were included in this study. These patients received luteal support with progesterone vaginal gel $600 \mathrm{mg} /$ day (Crinone, Merck Serono) initiated on day 1 after oocyte retrieval until endometrial collection (on day 7 after oocyte retrieval), similar to the regimen used for patients who underwent fresh-embryo-transfer.

Patients assigned to the control group were assessed during their natural cycles via transvaginal ultrasound scan every second day on days 7-9 of their menstrual cycle until detection of a dominant follicle with a diameter greater than $15 \mathrm{~mm}$. Further, the patients underwent daily ultrasonography and plasma $E_{2} /$ $\mathrm{LH} /$ progesterone measurement. Follicular disappearance and fluid appearance in the posterior cul-de-sac were confirmed by ultrasonography. Ovulation was also confirmed with the rise in $\mathrm{LH}$, drop in $\mathrm{E}_{2}$, and subsequent rise in progesterone levels $(P>6.0 \mathrm{ng} / \mathrm{mL}$ ) (Prior et al. 2015). Endometrial collection was performed on the day 7 after ovulation.

\section{Human endometrial tissue biopsy}

Human endometrial tissue samples were obtained during the mid-secretory phase, on the seventh day after ovulation $(n=6)$ or oocyte retrieval (GnRH-ant: $n=6$, GnRH-a: $n=6$ ), with single-use S-type endometrial biopsy tubes (TY-C3.1/30-1S; TianYi, Zhejiang, China). The samples were washed immediately in normal saline to completely remove residual blood and were divided into three parts. The first part was placed into $10 \%$ buffered formalin for paraffin embedding, the second was used for endometrial epithelial cell (EEC) isolation and actin polymerization assays, and the third was placed in liquid nitrogen until further use.

\section{Immunohistochemical analysis}

Paraffin-embedded sections were deparaffinized with xylene before being rehydrated via exposure to an ethanol series. 
Endogenous peroxidase activity was quenched using 3\% hydrogen peroxide in methanol, and the sections were then incubated overnight with anti-CKB or anti-HOXA10 antibodies (Supplementary Table 1, see section on supplementary materials given at the end of this article) in a humidified chamber at $4^{\circ} \mathrm{C}$. Secondary biotinylated antibodies and peroxidase-conjugated streptavidin were used in accordance with the manufacturer's instructions, and diaminobenzidine was used to produce a brown-colored deposit.

\section{Protein extraction and western blotting}

Endometrial tissue samples were lysed using RIPA lysis buffer (Thermo Fisher Scientific), treated with protease inhibitors, homogenized on ice, and centrifuged $(12,000 \mathrm{~g}$, $10 \mathrm{~min}, 4^{\circ} \mathrm{C}$ ) to facilitate protein collection. The extracted protein samples $(40 \mu \mathrm{g} /$ well) were then separated via SDSPAGE using $12 \%$ polyacrylamide gels and transferred to polyvinylidene difluoride membranes (Millipore). The membranes were blocked ( $1 \mathrm{~h}$, room temperature) with Trisbuffered saline (TBS) supplemented with $0.1 \%$ Tween-20 and $5 \%$ non-fat milk and immunoblotted (overnight, $4{ }^{\circ} \mathrm{C}$ ) with the primary antibody (Supplementary Table 1). After washing with TBS, the membranes were incubated (1 h, room temperature) with horseradish peroxidase-conjugated secondary antibodies (1:2000 dilution; product no. 7074; Cell Signaling Technology). The resulting signals were detected via enhanced chemiluminescence (Millipore), according to the manufacturer's instructions. Glyceraldehyde 3-phosphate dehydrogenase (GAPDH) was used as a loading control.

\section{Primary cell culture and treatment}

EECs were isolated from endometrial curettage samples $(n=6)$ collected using standard protocols following a hysteroscopic tubal patency assessment. EECs were then isolated from the collected cells according to a previously described protocol with some modifications (Zhang et al. 2012). Fresh endometrial tissues were minced prior to digestion via incubation with shaking for $1 \mathrm{~h}$ at $37^{\circ} \mathrm{C}$ in Dulbecco's modified Eagle's medium (DMEM)/F-12 containing 0.25\% type II collagenase (Gibco). The dispersed endometrial cells were then separated via filtration through a 40- $\mu$ m nylon cell strainer. Unfiltered glands were rinsed with $30 \mathrm{~mL}$ PBS and removed from the strainer. After centrifugation, EECs were initially seeded in 35-mm dishes in DMEM/F-12 medium and purified via transfer to new dishes. The cells were used after reaching $70-80 \%$ confluence. EECs were treated for $48 \mathrm{~h}$ with different concentrations $\left(10^{-5}\right.$ $\mathrm{mol} / \mathrm{L}, 10^{-8} \mathrm{~mol} / \mathrm{L}$ ) (Oztürk et al. 2010, Britten et al. 2012) of GnRH-a (Decapeptyl; Ferring), GnRH-ant (Cetrotide; Serono), or a solvent (control). Cells were then collected for quantitative PCR (qPCR), Western blotting, and/or actin polymerization analysis.

\section{Immunofluorescence colocalization}

EEC climbing films were fixed in 4\% paraformaldehyde for 20 min at $4{ }^{\circ} \mathrm{C}$. Slides were blocked (30 min) with $5 \%$ goat serum (Thermo Fisher Scientific) before being incubated overnight at $4^{\circ} \mathrm{C}$ with primary antibodies, including anti-GnRH-receptor (1:200) and anti-cytokeratin 7 (CK7) antibodies (1:200). After washing three times with PBS, the samples were incubated for $1 \mathrm{~h}$ at room temperature with appropriate fluorescently labeled secondary antibodies; 4',6-Diamidino-2-phenylindole (DAPI; 1:1000 dilution; product no. D9542; Sigma-Aldrich, Inc.) was employed to label cellular nuclei. The resulting fluorescence was analyzed using a laser-scanning confocal microscope (Carl Zeiss LSM-510).

\section{Ishikawa cell culture, treatment, and transfection with overexpression plasmids}

Ishikawa cells were seeded $\left(0.5 \times 10^{5} /\right.$ well $)$ in 24 -well plates, incubated overnight, and supplied with fresh DMEM/F-12 medium (without penicillin/streptomycin). Cells were then transfected with vectors with or without $C K B$-specific sequences (Genechem, Shanghai, China) using Lipofectamine 2000 (Thermo Fisher Scientific) according to the manufacturer's instructions. After $72 \mathrm{~h}$ of transfection, the cells were treated with different drugs for the indicated times and at the indicated concentrations.

\section{Lentiviral silencing of $C K B$}

Lentiviral plasmids containing shRNA sequences targeting $C K B$ (CKB-sh) or negative control (NC) were produced by Hanbio Company (Shanghai, China) and their transfection was performed according to the manufacturer's instructions. Briefly, Ishikawa cells (30\% confluence in six-well plates) were transfected with lentiviral plasmids. The culture medium was then replaced with transduction-enhancing solution containing lentivirus and $10 \mu \mathrm{g} / \mathrm{mL}$ polybrene. After $12 \mathrm{~h}$, the medium was replaced with complete medium, and the cells were cultured for $72 \mathrm{~h}$. The cells were then selected with $1 \mu \mathrm{g} / \mathrm{mL}$ puromycin/ streptomycin and harvested for subsequent studies. The target sequences for $C K B$ shRNA are listed in Table 1.

\section{ATP assay}

Total levels of cellular ATP were measured using a Luminescent ATP Detection Assay Kit (Abcam) according to the manufacturer's instructions. Briefly, EECs were seeded in 96-well plates, treated for $48 \mathrm{~h}$ with $\mathrm{GnRH}$-a or $\mathrm{GnRH}$-ant (final concentration $10^{-5}$ or $10^{-8} \mathrm{~mol} / \mathrm{L}$ ), and incubated $(700$ $\mathrm{rpm}, 5 \mathrm{~min})$ with detergent $(50 \mu \mathrm{L} /$ well $)$. After the addition of reconstitution substrate solution $(50 \mu \mathrm{L} /$ well), EECs were further incubated for $5 \mathrm{~min}$ with shaking at $700 \mathrm{rpm}$, and cellular ATP was measured using a luminescence spectrometer. Ishikawa cells transduced with negative or CKB knockdown lentivirus with or without $\mathrm{CKB}$ overexpression plasmid were evaluated to determine cellular ATP levels.

Table 1 Target sequences for $C K B$ shRNA.

\begin{tabular}{ll}
\hline ShRNA & Sequence $\left(5^{\prime}-3^{\prime}\right)$ \\
\hline$C K B$ sh 1 & TCGACGACCACTTCCTCTTCGACAA \\
$C K B$ sh2 & CATGAGAAGTTCTCGGAGGTGCTTA \\
$C K B$ sh3 & CCTACGAAGTGTTCAAGGATCTCTT \\
\hline
\end{tabular}




\section{Actin polymerization assay}

EEC or Ishikawa cell monolayers treated with or without specified stimuli were fixed with $4 \%$ formaldehyde, scraped, and loaded into 96-well plates. The cells were then permeabilized ( $5 \mathrm{~min}$ ) with $0.5 \%$ Triton X-100 and stained with Phalloidin (1:1000, $1 \mathrm{~h}$, room temperature; Sigma). The mean F-actin staining fluorescence intensity was analyzed using a laser-scanning confocal microscope (Carl Zeiss LSM-510).

\section{qPCR}

Total RNA was extracted from cultured Ishikawa cells using a spin column (RNeasy Mini Kit; Qiagen) according to the manufacturer's instructions, and reverse-transcription (RT) was conducted using RT Master Mix (Takara). qPCR was performed using an Applied Biosystems 7500 real-time PCR System (ABI, Singapore), SYBR Green Master Mix (Takara), and appropriate primers (Supplementary Table 2), according to the manufacturer's instructions. Generated data were analyzed using the $2^{-\Delta \Delta C t}$ method.

\section{Migration assay}

For the wound-healing experiments, the transfected cells were seeded separately into six-well plates $\left(1 \times 10^{6}\right.$ cells/well $)$ and cultured overnight. Once a monolayer of cells had formed, a $200-\mu \mathrm{L}$ pipette tip was used to scratch the cell layer. Cell debris was removed carefully with PBS, and cells were then cultured in serum-free medium to permit wound healing. Images were acquired at the same position under an inverted microscope at 0 or $24 \mathrm{~h}$ after scratching. Three independent experiments were conducted.

\section{Cell adhesion assay}

Cell adhesion was examined using $C K B$ shRNA-transduced cells or cells transfected with a $C K B$ overexpression plasmid. Ishikawa cells $\left(1 \times 10^{6}\right.$ cells $)$ were seeded into six-well plates and cultured for $24 \mathrm{~h}$. JAR cells were stained with PKH26 according to the manufacturer's protocol (Sigma) and then added to confluent Ishikawa monolayers in RPMI-1640 medium. These cocultured cells were cultured at $37^{\circ} \mathrm{C}$ in an incubator for $1 \mathrm{~h}$ and subjected to vigorous shaking at 140 rpm for 5 min before refreshing the medium. Finally, cells were imaged using an Olympus BX53M fluorescence microscope (Olympus). The number of counted cells in 4-5 randomly chosen areas in each well was used for statistical analysis. The experiment was repeated three times.

\section{Statistical analysis}

Statistical analyses were conducted using SAS 8.2 software (SAS Institute Inc.), and all data were expressed as means \pm standard errors of the means (S.E.M.S). Student's $t$-test was used to compare two groups. One-way ANOVA was used to compare three groups if normality (and homogeneity of variance) assumptions were satisfied, otherwise the Kruskal-Wallis test followed by Mann-Whitney $U$ test was used for analyzing the data. Differences in $P$ values of less than 0.05 were considered statistically significant.

\section{Results}

\section{Demographic characteristics}

Among the three groups, there were no significant differences in demographic characteristics. The average age, BMI, basal hormonal levels, and other parameters during COS of the antagonist and agonist groups were similar (Table 2).

\section{CKB and HOXA10 expression levels varied in endometrial tissues from patients in the different groups}

CKB production and localization were examined in endometrial tissues by immunohistochemical and Western blot analyses. CKB protein was strongly localized to the apical side of EECs during the receptive phase. However, CKB protein levels were obviously

Table 2 Clinical parameters of the patients. Data are presented as mean \pm S.D.

\begin{tabular}{|c|c|c|c|c|}
\hline & Control group $(n=6)$ & GnRH-ant group $(n=6)$ & GnRH-a group $(n=6)$ & $P$ value \\
\hline Age (year) & $29.5 \pm 1.9$ & $28.2 \pm 1.7$ & $29.7 \pm 2.1$ & 0.407 \\
\hline $\mathrm{BMI}$ & $21.4 \pm 1.2$ & $21.2 \pm 1.7$ & $21.1 \pm 1.6$ & 0.914 \\
\hline basal FSH (mIU/mL) & $6.4 \pm 0.7$ & $6.8 \pm 0.9$ & $6.7 \pm 1.1$ & 0.780 \\
\hline basal LH (mIU/mL) & $5.4 \pm 1.0$ & $5.9 \pm 1.1$ & $6.0 \pm 0.6$ & 0.588 \\
\hline basal $E_{2}(p g / m L)$ & $43.8 \pm 11.7$ & $51.5 \pm 8.7$ & $47.3 \pm 8.4$ & 0.479 \\
\hline Baseline antral follicle count & - & $9.7 \pm 2.1$ & $10.3 \pm 1.4$ & 0.570 \\
\hline Dosage of gonadotrophin (IU) & - & $2187.5 \pm 333.5$ & $2287.5 \pm 412.8$ & 0.654 \\
\hline Duration of stimulation (days) & - & $9.8 \pm 0.69$ & $10.8 \pm 0.9$ & 0.076 \\
\hline No. of oocytes retrieved & - & $11.3 \pm 2.4$ & $12.2 \pm 2.4$ & 0.593 \\
\hline $\begin{array}{l}\text { No. of mature follicles on the day of trigger } \\
\text { (diameter }>13 \mathrm{~mm} \text { ) }\end{array}$ & - & $8.7 \pm 1.5$ & $9.7 \pm 1.4$ & 0.296 \\
\hline $\mathrm{E}_{2}$ on the day when hCG was injected $(\mathrm{pg} / \mathrm{mL})$ & - & $4919.7 \pm 699.6$ & $4590.5 \pm 417.2$ & 0.387 \\
\hline P on the day when hCG was injected $(\mathrm{ng} / \mathrm{mL})$ & - & $1.10 \pm 0.21$ & $1.08 \pm 0.18$ & 0.855 \\
\hline Thickness of endometrium before ovulation (mm) & $8.8 \pm 0.4$ & $9.3 \pm 0.9$ & $9.0 \pm 0.6$ & 0.505 \\
\hline
\end{tabular}

$\mathrm{FSH}$, follicle-stimulating hormone; $\mathrm{LH}$, luteinizing hormone; $\mathrm{P}$, progesterone. 
reduced in GnRH-ant-treated endometrial samples compared with those in natural and $\mathrm{GnRH}$-a-treated samples (Fig. 1A, B and C). In addition, mRNA and protein levels of the molecular marker of endometrial receptivity HOXA10 in the analyzed endometrial tissues were assessed via qPCR, immunohistochemical staining, and Western blotting, respectively. Notably, HOXA10 mRNA and protein expression levels were significantly reduced in endometrium samples isolated from patients of the GnRH-a and GnRH-ant groups compared to those isolated from the control group. Furthermore,
HOXA10 mRNA and protein expression was lower in the $\mathrm{GnRH}$-ant than in the GnRH-a group (Fig. 1D, E, $\mathrm{F}$ and $\mathrm{G}$ ). Interestingly, EECs isolated from GnRH-anttreated endometrial samples showed reduced F-actin expression (Supplementary Fig. 1).

\section{GnRH-receptor expression on isolated EECs}

CK7 is a molecular marker of human EECs. Colocalization analyses showed that $\mathrm{GnRH}$ receptor was expressed in human EECs (Fig. 2).
A
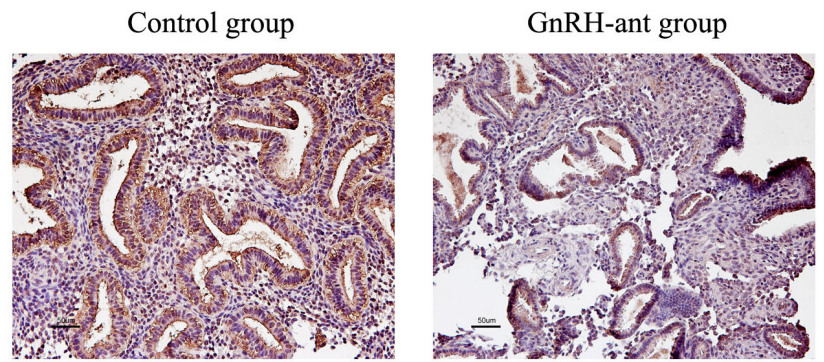

B

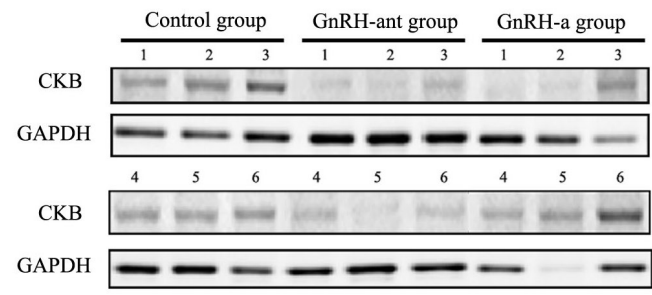

$\mathrm{D}$

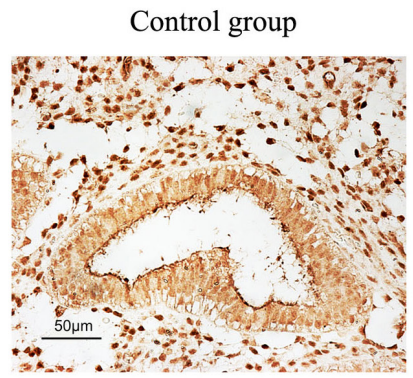

GnRH-ant group

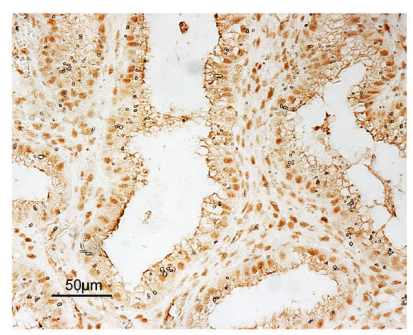

GnRH-a group

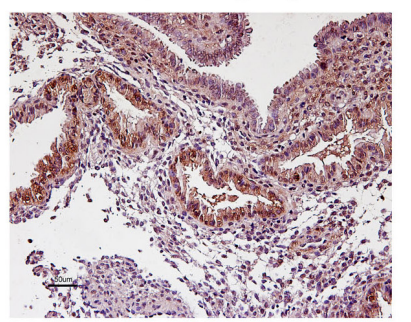

C

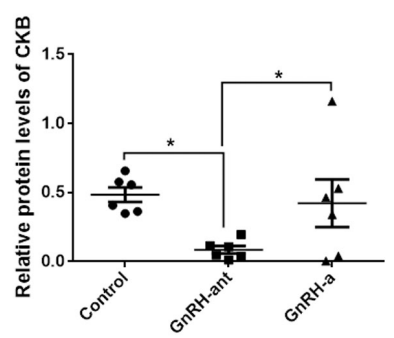

E

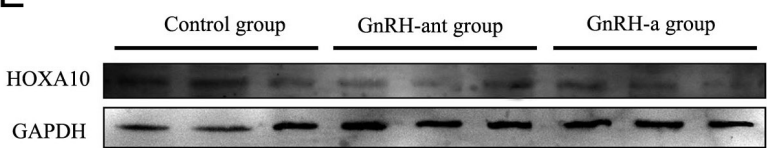

$\mathrm{F}$ ํํㅇ

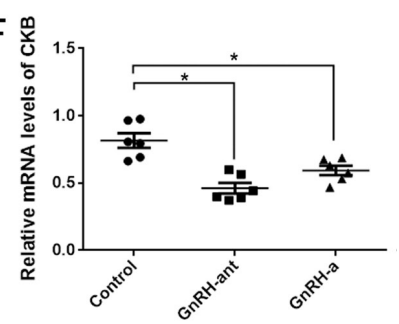

GnRH-a group

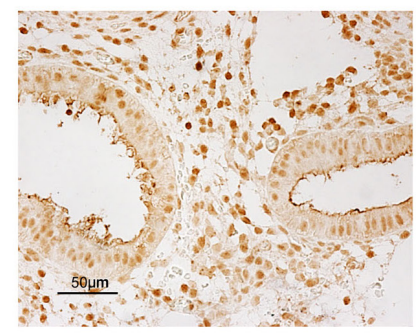

Figure $1 \mathrm{CKB}$ and HOXA10 expression levels varied in endometrial tissues in patients from different groups. (A) Immunohistochemical staining showing CKB levels in the natural (control), GnRH-ant, and GnRH-a patient groups. Scale bar $=50 \mu \mathrm{m}$. (B) Western blotting analysis of CKB expression levels. GAPDH (loading control) levels were used as a control for protein loading. (C) Densitometric measurement of CKB levels relative GAPDH expression. (D) Immunohistochemical staining of HOXA10 in the control, GnRH-ant, and GnRH-a patient groups. Scale bar $=50 \mu \mathrm{m}$. (E) Western blotting analysis of HOXA10 expression levels. (F) Densitometric measure of HOXA10 levels after normalization to GAPDH. (G) Quantitative real-time PCR analysis of HOXA10 mRNA expression after being normalized to that of GAPDH. ${ }^{*} P<0.05,{ }^{* *} P<0.01$. 
GnRH receptor

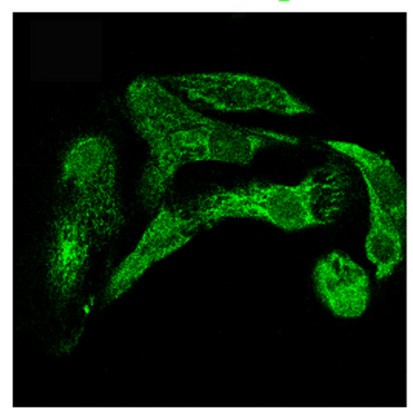

CK7

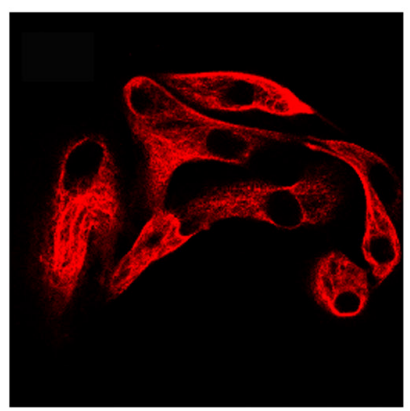

DAPI

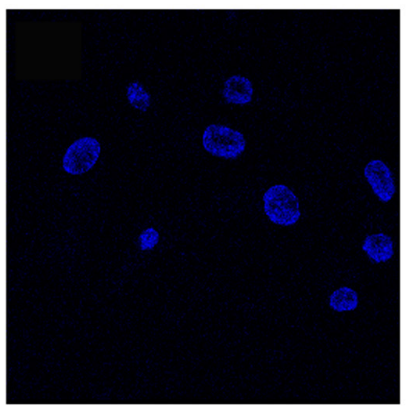

Merge

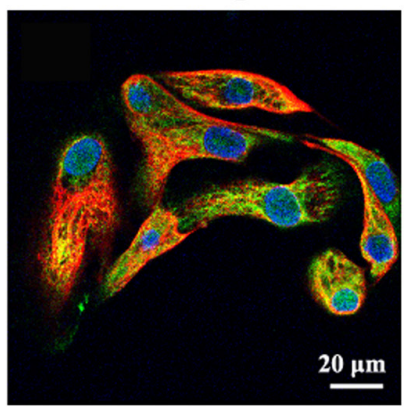

Figure 2 Immunofluorescence analysis showing CK7 and GnRH receptor localization in endometrial epithelial cells (EECs). Primary cultured EECs climbing films were stained for CK7 (red), GnRH receptor (green), and DAPI (blue). Scale bar $=20 \mu \mathrm{m}$.

GnRH-ant decreased CKB expression, ATP production, and actin polymerization in EECs

Cultured EECs were treated with two concentrations of GnRH-ant $\left(10^{-8}\right.$ and $10^{-5} \mathrm{~mol} / \mathrm{L}$ ) (Oztürk et al. 2010, Britten et al. 2012) to determine the dosage required to inhibit ATP generation. The results show that when EECs were exposed to the $\mathrm{GnRH}$ analog at $10^{-8} \mathrm{~mol} / \mathrm{L}$, there was little difference in ATP production (Supplementary Fig. 2). However, exposure of EECs to the GnRH analog at $10^{-5} \mathrm{~mol} / \mathrm{L}$ significantly inhibited ATP generation, and this effect was notably greater in the $\mathrm{GnRH}$-ant group than in the $\mathrm{GnRH}$-a group (Fig. 3A). CKB mRNA and protein expression was decreased in vitro after GnRH-ant treatment (Fig. 3C and D). At the same time, F-actin levels were reduced, and cell appeared shrunken (Fig. 3B).

\section{GnRH-ant decreased actin polymerization in vitro in Ishikawa cells, and overexpression of CKB rescued this effect}

Ishikawa cells were used to examine the influence of GnRH-ant on F-actin. Cells shrank and exhibited reduced F-actin levels after treatment with the $\mathrm{GnRH}$ analogs. Notably, these morphological changes were more obvious after exposure to GnRH-ant (Fig. 4B). Subsequent transfection of the Ishikawa cells with a $C K B$ overexpression vector led to a significant increase in $C K B$ mRNA levels by $48 \mathrm{~h}$ after transfection (Fig. 4A) and alleviation of F-actin inhibition in the $\mathrm{GnRH}$-ant group (Fig. 4B and C).

\section{CKB knockdown/overexpression affected actin polymerization, ATP levels, and migration of Ishikawa cells}

The effects of $C K B$ knockdown and overexpression in Ishikawa were examined using RT-qPCR and Western blotting (Fig. 5A, B, C, D, E and F). Ishikawa cells shrank and exhibited reduced $\mathrm{F}$-actin levels after $C K B$ shRNA transfection; this effect was rescued by $C K B$ overexpression (Fig. 5G). CKB shRNA also significantly inhibited ATP generation, and this effect was rescued after transfection with a $C K B$ overexpression plasmid (Fig. $5 \mathrm{H}$ ). The fluorescence intensity of fluorescencelabeled JAR cells adherent on CKB-knockdown or -overexpression Ishikawa cells was not obviously changed (Fig. 5I and J). The migration rate was decreased in CKB shRNA-transduced Ishikawa cells compared with that in mock-transduced Ishikawa cells, and this effect could be rescued by $C K B$ overexpression (Fig. $5 \mathrm{~K}$ and $\mathrm{L}$ ).

\section{Discussion}

CKB regulates the reservoir of rapidly mobilized high-energy phosphates in tissues such as the brain by reversibly catalyzing the transfer of the highenergy phosphate group between ATP and various phosphorylated molecules, yielding phosphocreatine (Wyss \& Kaddurah-Daouk 2000). CKB levels are significantly increased in endometrial WOI (Parmar et al.
A
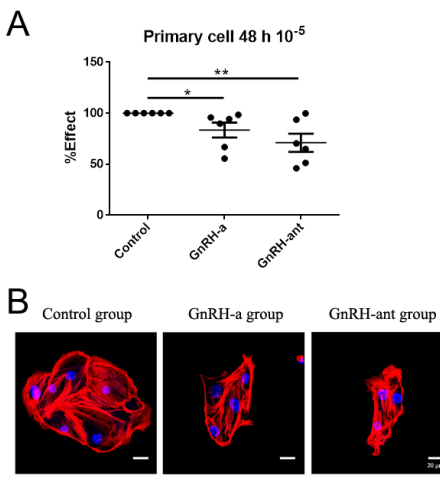
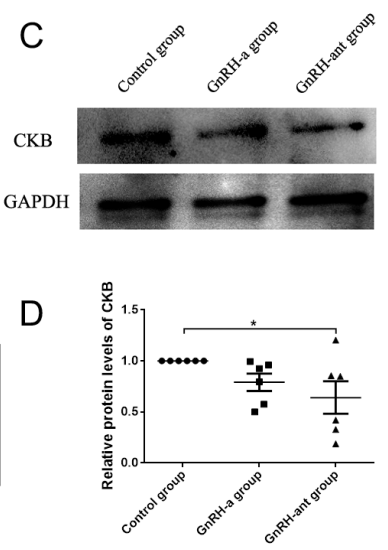

Figure $3 \mathrm{GnRH}$-ant decreased $C K B$ expression, ATP production, and actin polymerization in EECs. (A) In vitro ATP levels in primary cultured EECs $(n=6)$. (B) Confocal analysis of F-actin content in EECs in vitro (F-actin, red; DAPI, blue). Scale bar $=20 \mu \mathrm{m}$. (C) Western blotting analysis of in vitro CKB levels in EECs. (D) Densitometric measurement of CKB levels relative to GAPDH expression. ${ }^{*} P<0.05$, $* * P<0.01$. 
A

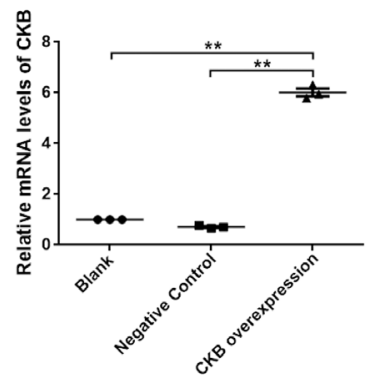

B

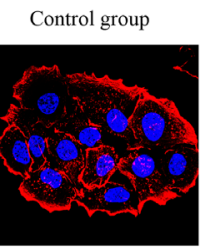

GnRH-a group

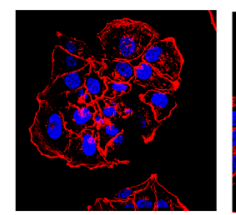

GnRH-ant group

Blank
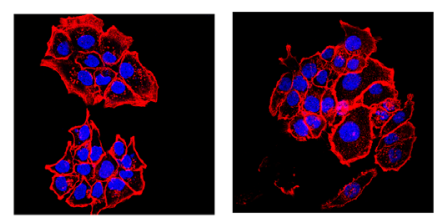

Negative control
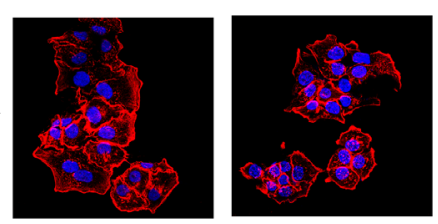

C

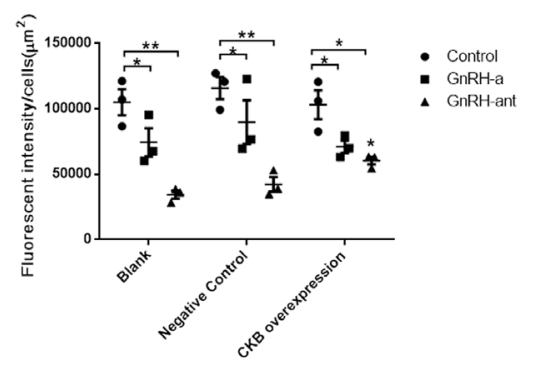

Figure $4 \mathrm{GnRH}$-ant decreased actin polymerization in vitro in Ishikawa cells, and overexpression of $C K B$ rescued this effect. (A) RT-qPCR analysis of the efficiency achieved during transfection of Ishikawa cells with CKB expression plasmids in vitro. (B) Confocal analysis of F-actin content in Ishikawa cells in vitro (F-actin, red and DAPI, blue). Scale bar $=20 \mu \mathrm{m}$. (C) Fluorescent intensity/cell = mean fluorescent intensity $\times$ area of the cell. ${ }^{*} P<0.05, * * P<0.01$.

2009, Chen et al. 2015), suggesting that CKB may be required to achieve the endometrial receptive state. These findings are supported by the observation that CKB is predominantly expressed on the luminal surface of EECs, which are the first uterine cells to contact the embryo. Correct embryo implantation is necessary for the success of a pregnancy and is related to metabolic changes in uterine cells, such as glycogen accumulation (Frolova \& Moley 2011). From the late proliferative phase to the secretion phase, glycogen accumulates in human uterine glandular and luminal epithelial cells in a manner likely required to regulate energy homeostasis during embryo implantation (Verma 1983, Cornillie et al. 1985, Spornitz 1992). Given that hypoxic conditions are maintained during normal embryonic development and endometrial differentiation (Hustin et al. 1990, Jauniaux et al. 2000), normal increases in CKB levels, similar to accumulated glycogen, during the WOI may represent an adaptive response to maintain the energy balance. Creatine kinase transforms phosphocreatine into ATP and creatine to meet increased cellular energy requirements in a low ATP state (Wallimann et al. 2011, Chen et al. 2013), allowing the endometrium to maintain its energy balance under hypoxic conditions occurring during early pregnancy. In this study, decreased CKB expression was found in biopsy tissues from the $\mathrm{GnRH}$-ant group. In addition, expression of the endometrial receptivity marker HOXA10, whose expression is a prerequisite for endometrial receptivity (Bagot et al. 2000, Taylor 2000), was considerably reduced in the $\mathrm{GnRH}$-ant group. Consistent with the present study, other studies have previously suggested that the $\mathrm{GnRH}$-ant likely reduces HOXA10 expression during the endometrial WOI (Rackow et al. 2008, Li et al. 2015). Thus, the GnRHant reduces CKB expression, which may be related to insufficient endometrial receptivity. Subsequently, in vitro analyses revealed that treatment of EECs with $\mathrm{GnRH}$ analogs for $48 \mathrm{~h}$ at $10^{-5} \mathrm{~mol} / \mathrm{L}$ inhibited ATP generation and that this effect was more obvious after treatment with $\mathrm{GnRH}$-ant than with $\mathrm{GnRH}$-a. Moreover, CKB expression in EECs decreased significantly after treatment with $\mathrm{GnRH}$-ant. Therefore, the inhibition of ATP generation and reduced CKB levels observed in the present study suggested that $\mathrm{GnRH}$-ant treatment may disrupt cellular energy balance during formation of the endometrial receptive state.

EECs isolated from $\mathrm{GnRH}$-ant-treated endometrial samples showed reduced F-actin expression. In addition, in vitro analyses showed that $\mathrm{GnRH}$-ant treatment reduced F-actin expression in both EECs and Ishikawa cells. The abnormal F-actin expression observed was suggestive of actin fiber depolymerization, which may directly affect the basic functions of cells. Interestingly, the $\mathrm{GnRH}$-ant-induced depolymerization of F-actin was rescued partly via $C K B$ overexpression, suggesting that the energy metabolism status is likely related to F-actin polymerization. Cytoskeletal polymerization and depolymerization processes require energy; thus, insufficient energy reserves may lead to imbalances in these processes. Most functions of EECs during WOI are closely related to changes in the cytoskeleton (Demir et al. 2002, Png \& Murphy 2002, Hosie et al. 2008); thus, the presence of an abnormal cytoskeleton is expected to disrupt endometrial receptivity. Notably, in this study, GnRH-ant treatment was found to disrupt the cellular energy balance and directly induce cytoskeleton damage, which may further affect endometrial receptivity. Thus, endometrial receptivity is likely dependent on the maintenance of correct 
A

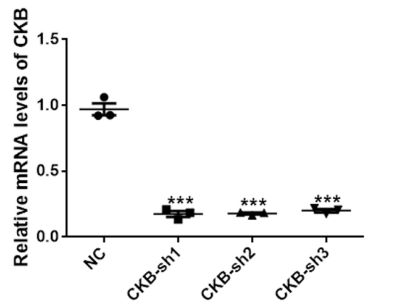

D

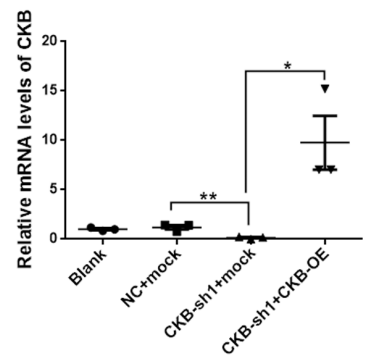

B

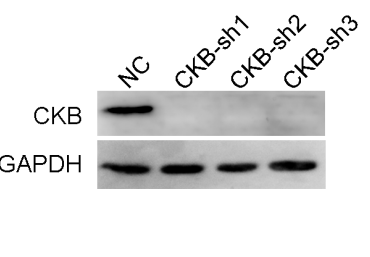

E

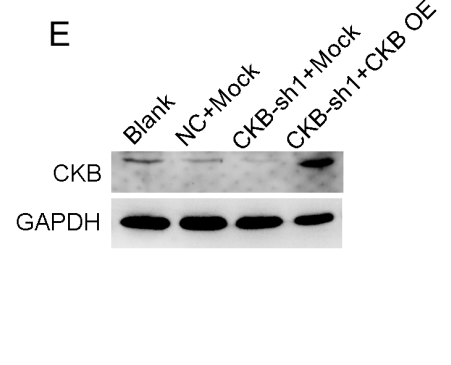

C

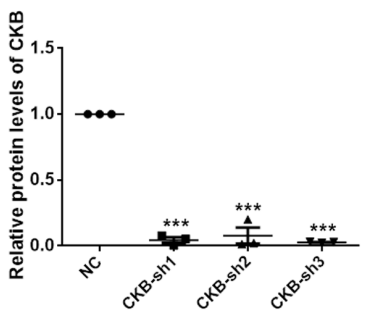

$\mathrm{F}$

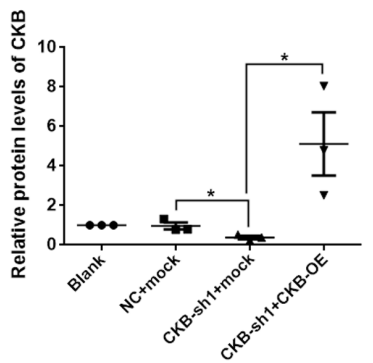

G
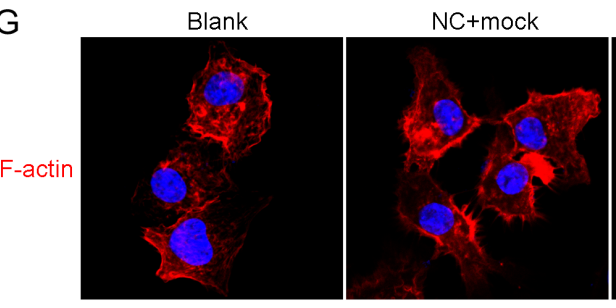

I
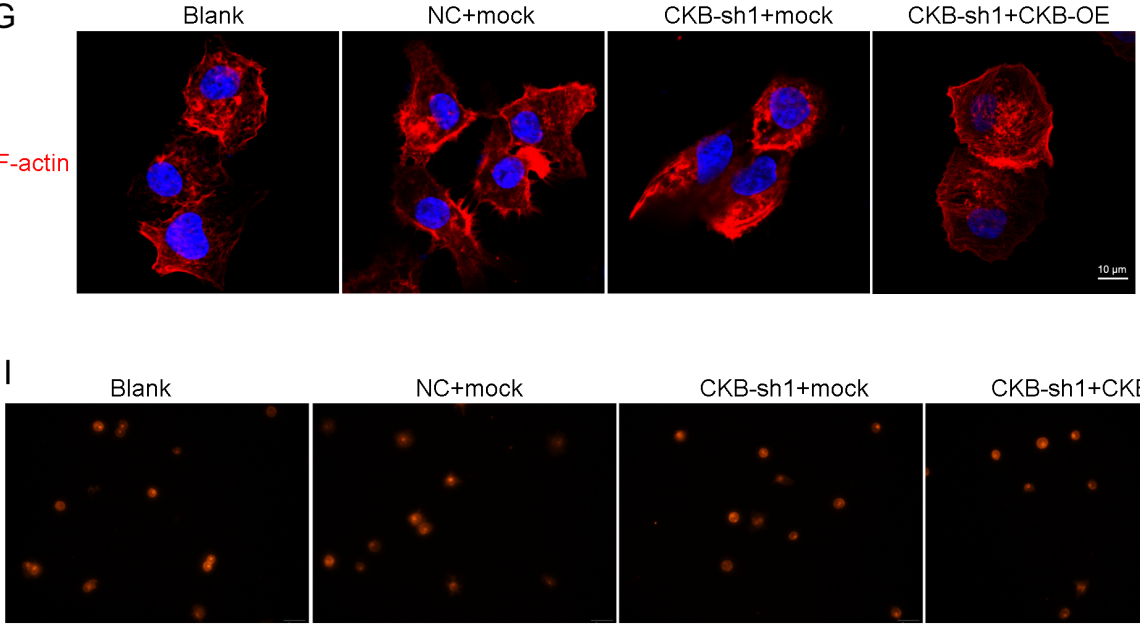

$10 \mathrm{\mu m}$

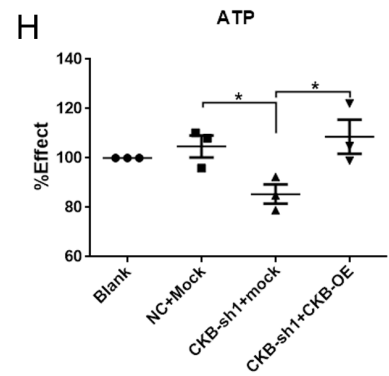

CKB-sh1+CKB-OE
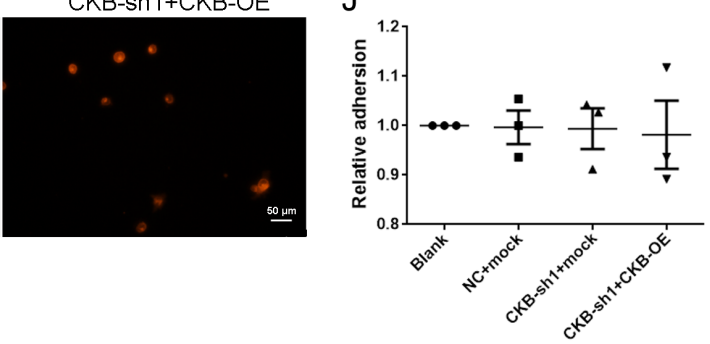

$\mathrm{K}$

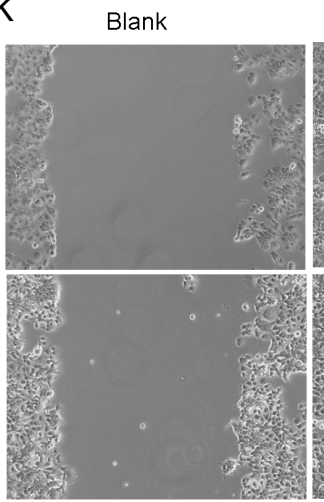

$\mathrm{NC}+$ mock

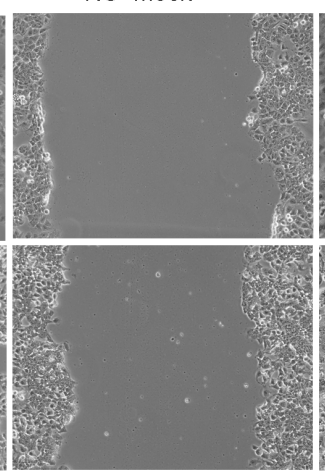

CKB-sh1+CKB-OE

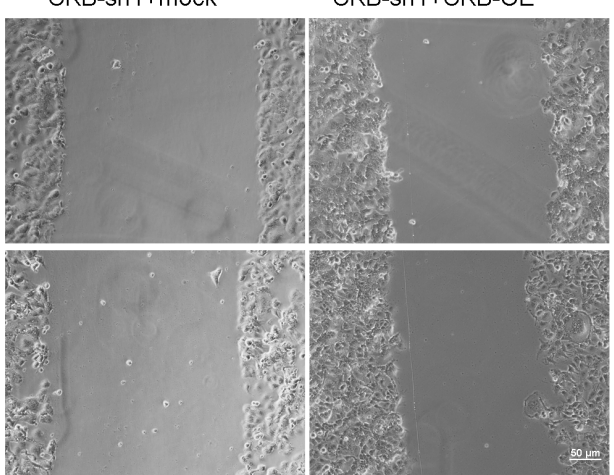

L

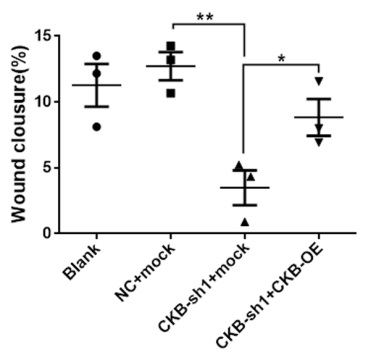

Figure $5 C K B$ knockdown/overexpression affected actin polymerization, ATP levels, and migration in Ishikawa cells. (A, B and C) $C K B$ expression levels after $C K B$ silencing in Ishikawa cells using RT-qPCR and western blotting. (D, E and F) Ishikawa cells were transfected with control shRNA, CKB shRNA, or a combination of mock and CKB plasmids. CKB expression levels were detected using RT-qPCR and Western blotting. (G) F-actin content in control and treated Ishikawa cells. (H) In vitro ATP levels in control and treated Ishikawa cells. (I and J) Analysis of JAR spheroid adhesion on Ishikawa cells after CKB shRNA or CKB plasmid transfection. (K) Wound healing assay in Ishikawa cells transfected with negative shRNA, CKB shRNA, or mock and CKB plasmids. Wound width was measured at 0 and $24 \mathrm{~h}$ after wounding. (L) Histograms showing quantification of the results (wound closure). All data are presented as means \pm S.E.M.S. ${ }^{*} P<0.05 ;{ }^{* *} P<0.01 ;{ }^{* * *} P<0.001$. 
energy metabolism, necessitating normal cytoskeleton structure.

In this study, ATP generation was found to be reduced with $C K B$ knockdown. Additionally, actin polymerization decreased, and cell migration also decreased. However, there were no significant changes in cell adhesion. The opposite results were observed when $C K B$ was overexpressed. Accordingly, CKB was involved in the regulation of actin polymerization/depolymerization and could ultimately affect the migration of EECs. Importantly, many studies have shown that changes in the cytoskeleton can directly affect cell migration (Flamini et al. 2011, Fife et al. 2014, Tang \& Gerlach 2017). Thus, the effects of the antagonists on changes in CKB and the cytoskeleton may lead to changes in epithelial cell migration.

CKB has been shown to have a role in cancer cell migration (Christofk et al. 2008, Dang et al. 2009, Cairns et al. 2011, Kaelin \& McKnight 2013) and tumor progression. Indeed, combination therapy including CKB inhibition significantly suppresses colon cancer metastasis (Loo et al. 2015). Migration is also a key step during implantation. However, the role of CKB in embryo implantation has not been reported. During embryo implantation, blastocysts attach to and then invade the epithelium to enter the underlying stroma. During the early stage of this process, the EEC barrier is disrupted. To achieve embryonic penetration, EECs migrate away from the implantation site, and EEC migration and invasion can facilitate the restructuring of the disrupted endometrial epithelium. The embryo is then covered with epithelial cells, resulting in restoration of the EEC barrier (Cui et al. 2018). The dysfunction of epithelial migration affects endometrial receptivity. In this study, CKB silencing/overexpression was found to alter endometrial cell migration and invasion, further suggesting that CKB was closely related to the establishment of endometrial receptivity. GnRH-ant can lead to insufficient production of CKB and ATP, thereby affecting the migration of epithelial cells. This may be a fundamental reason for the decline in endometrial receptivity caused by $\mathrm{GnRH}$-ant.

In peripheral blood circulation, endogenous GnRH levels were very low. Therefore, the biological effects of the combination of $\mathrm{GnRH}$ and $\mathrm{GnRH}$ receptor outside the hypophysis gland are extremely low (Ortmann \& Diedrich 1999). However, the affinity of the GnRHant (Cetrorelix) to the $\mathrm{GnRH}$ receptor was 20 and 2 times higher than those of natural $\mathrm{GnRH}$ and $\mathrm{GnRH}-\mathrm{a}$ (buserelin), respectively (Reissmann et al. 2000). Therefore, the $\mathrm{GnRH}$-ant is more likely to combine with the GnRH receptor outside the hypophysis gland, including the endometrium (Ramakrishnappa et al. 2005). In this study, the identification of the GnRH receptor in EECs further confirmed this possibility. Several human malignant tumors, including cancers of the endometrium, ovary, breast, prostate, and urinary bladder, express GnRH and its receptor as part of an autocrine system that regulates cell proliferation (Grundker et al. 2002). Various investigators have observed time- and dose-dependent growth inhibitory effects of $\mathrm{GnRH}$-ant in cell lines derived from these cancers (Emons et al. 2003, Dondi et al. 2006). Although the precise mechanisms remain unclear, it is believed that the well-known signaling mechanisms present in pituitary gonadotrophs of the $\mathrm{GnRH}$ receptor are not involved in forwarding the anti-metastatic and antiproliferative effects of $\mathrm{GnRH}$ analogs in cancer cells. Instead, $\mathrm{GnRH}$ analogs may inhibit cancer cell metastasis and proliferation by reducing the synthesis of local growth factors in a dose-dependent manner (Grundker \& Emons 2017). However, there are few reports assessing the effects of the $\mathrm{GnRH}$-ant on normal uterine epithelial cells. Despite advancements in this study, the molecular mechanisms through which CKB reduced and inhibited endometrial cell migration in women undergoing the $\mathrm{GnRH}$-ant protocol were not clarified. GnRH-ant may also affect the expression of CKB by changing the concentration of local growth factors, leading to a series of biological effects, but this has yet to be confirmed. Therefore, more in-depth studies are required and are currently underway.

\section{Conclusions}

In summary, GnRH-ant affected CKB expression in EECs. These effects could damage the cytoskeleton, disrupt cell migration, and alter endometrial receptivity. These findings established CKB as a new therapeutic target for improving endometrial receptivity in the clinical setting and indicated that although the $\mathrm{GnRH}$-ant protocol may effectively induce multifollicle ovulation, its negative effects should also be considered and managed to facilitate the design of improved clinical therapeutic regimens.

\section{Supplementary materials}

This is linked to the online version of the paper at https://doi. org/10.1530/REP-19-0572.

\section{Declaration of interest}

The authors declare that there is no conflict of interest that could be perceived as prejudicing the impartiality of the research reported.

\section{Funding}

This work was supported by the National Natural Science Foundation of China (grant numbers 81671517, 81873857, and 81571397) and the Shanghai Municipal Commission of Health and Family Planning (grant number 20164Y0137). 


\section{Author contribution statement}

Q C and C X designed the study. Q C, Y F, and X W Z performed the study. ZY and $Y$ P K participated in parts of the experiments and analysis of the data. Q C, A J Z, and C X wrote the paper. All authors read and approved the final manuscript.

\section{References}

Al-Inany HG, Abou-Setta AM \& Aboulghar M 2007 Gonadotrophinreleasing hormone antagonists for assisted conception: a Cochrane review. Reproductive Biomedicine Online 14 640-649. (https://doi. org/10.1016/s1472-6483(10)61059-0)

Bagot CN, Troy PJ \& Taylor HS 2000 Alteration of maternal Hoxa10 expression by in vivo gene transfection affects implantation. Gene Therapy 7 1378-1384. (https://doi.org/10.1038/sj.gt.3301245)

Britten JL, Malik M, Levy G, Mendoza M \& Catherino WH 2012 Gonadotropin-releasing hormone $(\mathrm{GnRH})$ agonist leuprolide acetate and $\mathrm{GnRH}$ antagonist cetrorelix acetate directly inhibit leiomyoma extracellular matrix production. Fertility and Sterility 98 1299-1307. (https://doi.org/10.1016/j.fertnstert.2012.07.1123)

Bukulmez O, Carr BR, Doody KM \& Doody KJ 2008 Serum cetrorelix concentrations do not affect clinical pregnancy outcome in assisted reproduction. Fertility and Sterility 89 74-83. (https://doi.org/10.1016/j. fertnstert.2007.02.017)

Cairns RA, Harris IS \& Mak TW 2011 Regulation of cancer cell metabolism. Nature Reviews: Cancer 11 85-95. (https://doi.org/10.1038/nrc2981)

Chen Y, Wu J, Tu L, Xiong X, Hu X, Huang J, Xu Z, Zhang X, Hu C, Hu X et al. $2013 \mathrm{H}-\mathrm{NMR}$ spectroscopy revealed Mycobacterium tuberculosis caused abnormal serum metabolic profile of cattle. PLOS ONE 8 e74507. (https://doi.org/10.1371/journal.pone.0074507)

Chen Q, Zhang A, Yu F, Gao J, Liu Y, Yu C, Zhou H\& Xu C 2015 Label-free proteomics uncovers energy metabolism and focal adhesion regulations responsive for endometrium receptivity. Journal of Proteome Research 14 1831-1842. (https://doi.org/10.1021/acs.jproteome.5b00038)

Christofk HR, Vander Heiden MG, Harris MH, Ramanathan A, Gerszten RE, Wei R, Fleming MD, Schreiber SL \& Cantley LC 2008 The M2 splice isoform of pyruvate kinase is important for cancer metabolism and tumour growth. Nature 452 230-233. (https://doi.org/10.1038/nature06734)

Cornillie FJ, Lauweryns JM \& Brosens IA 1985 Normal human endometrium. An ultrastructural survey. Gynecologic and Obstetric Investigation 20 113-129. (https://doi.org/10.1159/000298983)

Cui D, Sui L, Han X, Zhang M, Guo Z, Chen W, Yu X, Sun Q, Dong M, Ma T et al. 2018 Aquaporin-3 mediates ovarian steroid hormoneinduced motility of endometrial epithelial cells. Human Reproduction 33 2060-2073. (https://doi.org/10.1093/humrep/dey290)

Dang L, White DW, Gross S, Bennett BD, Bittinger MA, Driggers EM, Fantin VR, Jang HG, Jin S, Keenan MC et al. 2009 Cancer-associated IDH1 mutations produce 2-hydroxyglutarate. Nature 462 739-744. (https://doi.org/10.1038/nature08617)

Demir R, Kayisli UA, Celik-Ozenci C, Korgun ET, Demir-Weusten AY \& Arici A 2002 Structural differentiation of human uterine luminal and glandular epithelium during early pregnancy. An ultrastructural and immunohistochemical study. Placenta 23 672-684. (https://doi. org/10.1053/plac.2002.0841)

Devroey P, Aboulghar M, Garcia-Velasco J, Griesinger G, Humaidan P, Kolibianakis E, Ledger W, Tomás C \& Fauser BC 2009 Improving the patient's experience of IVF/ICSI: a proposal for an ovarian stimulation protocol with GnRH antagonist co-treatment. Human Reproduction 24 764-774. (https://doi.org/10.1093/humrep/den468)

Dondi D, Festuccia C, Piccolella M, Bologna M \& Motta M 2006 GnRH agonists and antagonists decrease the metastatic progression of human prostate cancer cell lines by inhibiting the plasminogen activator system. Oncology Reports 15 393-400. (https://doi.org/10.3892/or.15.2.393)

Eftekhar M, Dehghani Firouzabadi R, Karimi H \& Rahmani E 2012 Outcome of cryopreserved-thawed embryo transfer in the $\mathrm{GnRH}$ agonist versus antagonist protocol. Iranian Journal of Reproductive Medicine 10 297-302.

Emons G, Grundker C, Gunthert AR, Westphalen S, Kavanagh J \& Verschraegen C 2003 GnRH antagonists in the treatment of gynecological and breast cancers. Endocrine-Related Cancer 10 291-299. (https://doi. org/10.1677/erc.0.0100291)

Fife CM, McCarroll JA \& Kavallaris M 2014 Movers and shakers: cell cytoskeleton in cancer metastasis. British Journal of Pharmacology 171 5507-5523. (https://doi.org/10.1111/bph.12704)

Flamini MI, Sanchez AM, Genazzani AR \& Simoncini T 2011 Estrogen regulates endometrial cell cytoskeletal remodeling and motility via focal adhesion kinase. Fertility and Sterility 95 722-726. (https://doi. org/10.1016/j.fertnstert.2010.08.039)

Frolova Al \& Moley KH 2011 Glucose transporters in the uterus: an analysis of tissue distribution and proposed physiological roles. Reproduction 142 211-220. (https://doi.org/10.1530/REP-11-0114)

Grundker C \& Emons G 2017 The role of gonadotropin-releasing hormone in cancer cell proliferation and metastasis. Frontiers in Endocrinology $\mathbf{8}$ 187. (https://doi.org/10.3389/fendo.2017.00187)

Grundker C, Gunthert AR, Westphalen S \& Emons G 2002 Biology of the gonadotropin-releasing hormone system in gynecological cancers. European Journal of Endocrinology 146 1-14. (https://doi.org/10.1530/ eje.0.1460001)

Hernandez ER 2000 Embryo implantation and GnRH antagonists: embryo implantation: the Rubicon for GnRH antagonists. Human Reproduction 15 1211-1216. (https://doi.org/10.1093/humrep/15.6.1211)

Hosie M, Adamson M \& Penny C 2008 Actin binding protein expression is altered in uterine luminal epithelium by clomiphene citrate, a synthetic estrogen receptor modulator. Theriogenology 69 700-713. (https://doi. org/10.1016/j.theriogenology.2007.12.002)

Hustin J, Jauniaux E \& Schaaps JP 1990 Histological study of the maternoembryonic interface in spontaneous abortion. Placenta 11 477-486. (https://doi.org/10.1016/s0143-4004(05)80193-6)

Jauniaux E, Watson AL, Hempstock J, Bao YP, Skepper JN \& Burton GJ 2000 Onset of maternal arterial bloodflow and placental oxidative stress. A possible factor in human early pregnancy failure. American Journal of Pathology 157 2111-2122. (https://doi.org/10.1016/S00029440(10)64849-3)

Kaelin Jr WG \& McKnight SL 2013 Influence of metabolism on epigenetics and disease. Cell 153 56-69. (https://doi.org/10.1016/j.cell.2013.03.004)

Kim ST \& Moley KH 2009 Regulation of facilitative glucose transporters and AKT/MAPK/PRKAA signaling via estradiol and progesterone in the mouse uterine epithelium. Biology of Reproduction 81 188-198. (https:// doi.org/10.1095/biolreprod.108.072629)

Lambalk CB, Banga FR, Huirne JA, Toftager M, Pinborg A, Homburg R, van der Veen F \& van Wely M 2017 GnRH antagonist versus long agonist protocols in IVF: a systematic review and meta-analysis accounting for patient type. Human Reproduction Update 23 560-579. (https://doi. org/10.1093/humupd/dmx017)

Li F, Zhang M, Zhang Y, Liu T \& Qu X 2015 GnRH analogues may increase endometrial Hoxa10 promoter methylation and affect endometrial receptivity. Molecular Medicine Reports 11 509-514. (https://doi. org/10.3892/mmr.2014.2680)

Loo JM, Scherl A, Nguyen A, Man FY, Weinberg E, Zeng Z, Saltz L, Paty PB \& Tavazoie SF 2015 Extracellular metabolic energetics can promote cancer progression. Cell 160 393-406. (https://doi.org/10.1016/j. cell.2014.12.018)

Ortmann O \& Diedrich K 1999 Pituitary and extrapituitary actions of gonadotrophin-releasing hormone and its analogues. Human Reproduction 14 (Supplement 1) 194-206. (https://doi.org/10.1093/ humrep/14.suppl_1.194)

Orvieto R \& Patrizio P 2013 GnRH agonist versus GnRH antagonist in ovarian stimulation: an ongoing debate. Reproductive Biomedicine Online 26 4-8. (https://doi.org/10.1016/j.rbmo.2012.11.001)

Oztürk HB, Vural B, Calışkan E \& Solakoğlu S 2010 Effect of GnRH analogues and octreotide treatment on apoptosis and the cell proliferation of endometrium adenocarcinoma cell lines. Journal of the Turkish German Gynecological Association 11 131-136. (https://doi.org/10.5152/ jtgga.2010.19)

Parmar T, Gadkar-Sable S, Savardekar L, Katkam R, Dharma S, Meherji P, Puri CP \& Sachdeva G 2009 Protein profiling of human endometrial tissues in the midsecretory and proliferative phases of the menstrual cycle. Fertility and Sterility 92 1091-1103. (https://doi.org/10.1016/j. fertnstert.2008.07.1734)

Png FY \& Murphy CR 2002 Cytoskeletal proteins in uterine epithelial cells only partially return to the pre-receptive state after the period 
of receptivity. Acta Histochemica $104 \quad 235-244 . \quad$ (https://doi. org/10.1078/0065-1281-00652)

Prapas N, Prapas Y, Panagiotidis Y, Prapa S, Vanderzwalmen P, Schoysman R \& Makedos G $2005 \mathrm{GnRH}$ agonist versus GnRH antagonist in oocyte donation cycles: a prospective randomized study. Human Reproduction 20 1516-1520. (https://doi.org/10.1093/humrep/deh832)

Prior JC, Naess M, Langhammer A \& Forsmo S 2015 Ovulation prevalence in women with spontaneous normal-length menstrual cycles - a population-based cohort from HUNT3, Norway. PLOS ONE 10 e0134473. (https://doi.org/10.1371/journal.pone.0134473)

Rackow BW, Kliman HJ \& Taylor HS 2008 GnRH antagonists may affect endometrial receptivity. Fertility and Sterility 89 1234-1239. (https://doi. org/10.1016/j.fertnstert.2007.04.060)

Ramakrishnappa N, Rajamahendran R, Lin YM \& Leung PC 2005 $\mathrm{GnRH}$ in non-hypothalamic reproductive tissues. Animal Reproduction Science $\mathbf{8 8}$ 95-113. (https://doi.org/10.1016/j.anireprosci.2005. 05.009)

Reissmann T, Schally AV, Bouchard P, Riethmiiller H \& Engel J 2000 The LHRH antagonist cetrorelix: a review. Human Reproduction Update $\mathbf{6}$ 322-331. (https://doi.org/10.1093/humupd/6.4.322)

Ruan HC, Zhu XM, Luo Q, Liu AX, Qian YL, Zhou CY, Jin F, Huang HF \& Sheng JZ 2006 Ovarian stimulation with GnRH agonist, but not GnRH antagonist, partially restores the expression of endometrial integrin beta 3 and leukaemia-inhibitory factor and improves uterine receptivity in mice. Human Reproduction 21 2521-2529. (https://doi.org/10.1093/ humrep/del215)

Spornitz UM 1992 The functional morphology of the human endometrium and decidua. Advances in Anatomy, Embryology, and Cell Biology 124 1-99. (https://doi.org/10.1007/978-3-642-58099-4)

Tang DD \& Gerlach BD 2017 The roles and regulation of the actin cytoskeleton, intermediate filaments and microtubules in smooth muscle cell migration. Respiratory Research 18 54. (https://doi.org/10.1186/ s12931-017-0544-7)
Tarlatzis BC \& Bili HN 2003 Gonadotropin-releasing hormone antagonists: impact of IVF practice andpotential non-assisted reproductive technology applications. Current Opinion in Obstetrics and Gynecology 15 259-264. (https://doi.org/10.1097/00001703-200306000-00009)

Taylor HS 2000 The role of HOX genes in human implantation. Human Reproduction Update 6 75-79. (https://doi.org/10.1093/humupd/6.1.75)

Verma V 1983 Ultrastructural changes in human endometrium at different phases of the menstrual cycle and their functional significance. Gynecologic and Obstetric Investigation 15 193-212. (https://doi. org/10.1159/000299412)

Wallimann T, Tokarska-Schlattner M \& Schlattner U 2011 The creatine kinase system and pleiotropic effects of creatine. Amino Acids $\mathbf{4 0}$ 1271-1296. (https://doi.org/10.1007/s00726-011-0877-3)

Wyss M \& Kaddurah-Daouk R 2000 Creatine and creatinine metabolism. Physiological Reviews 80 1107-1213. (https://doi.org/10.1152/ physrev.2000.80.3.1107)

Xu B, Zhou M, Wang J, Zhang D, Guo F, Si C, Leung PCK \& Zhang A 2018 Increased AIF-1-mediated TNF- $\alpha$ expression during implantation phase in IVF cycles with GnRH antagonist protocol. Human Reproduction 33 1270-1280. (https://doi.org/10.1093/humrep/dey119)

Zhang D, Ma C, Sun X, Xia H \& Zhang W 2012 S100P expression in response to sex steroids during the implantation window in human endometrium. Reproductive Biology and Endocrinology 10 106. (https:// doi.org/10.1186/1477-7827-10-106)

Received 30 November 2019

First decision 7 January 2020

Revised manuscript received 16 March 2020

Accepted 26 March 2020 